\title{
A FRAMEWORK FOR EXPLORING IT-LED CHANGE IN MORPHING ORGANIZATIONS
}

\author{
Abstract \\ Organizations need to continually adjust in response to changes in their environment in order to \\ survive. Organizational transformation refers to changes in the way in which an organization \\ operates. Morphing organization is a term used to reflect organizational transformation, \\ recognizing that as an organization changes the outer face the organization displays to the world, \\ changes are also needed to the internal structures and processes within the organization to \\ facilitate and support the external face. IT-led change is a major driver for organizational \\ transformation. This chapter presents an organization architecture which can be used to explore \\ the impact of IT-led change on organizations.
}

IT has changed the structure and face of organizations in most industries and it is recognized that introducing and changing technology in an organization is not merely an IT issue. For example, the impact of ebusiness transformation of organizations is well documented. The wider implications of changing IT systems in organizations as an enabler of organizational change need to be considered.

The contribution of this chapter is the presentation of an organizational architecture as a framework to structure analysis and evaluation of the aspects of an organization that may be affected by proposed changes to IT systems in an organization. The framework offers a coherent structure in which to consider organizational transformation in response to IT-led change. The framework may also be used retrospectively to analyse how changes in IT have led to organizational transformation. The organizational architecture builds on the $7 \mathrm{~s}$ model and considers the impact of IT changes to both formal elements of the organization such as organizational structure and informal elements such as social values. The application of the organization architecture is illustrated through case study examples from UK organizations.

\section{INTRODUCTION}

Organizations must continually change to survive, adapting to changes in their social, economic and trading environments, responding to the changing needs of customers and reacting to competition. Organizational transformation refers to changes in the way in which an organization operates. Morphing organization is a term used to reflect organizational transformation, recognizing that as an organization changes its outer face displayed to the world, internal structures and processes within the organization must change to facilitate and support the external interface. A morphing organization has an identity that is determined by the organization's relationship with its environment, its internal components and the social practices in which the participants in the organization interact. As the external face of the organization changes and internal components are adjusted, core structures and values need to be retained in order to maintain the organization's unique identity (Cox, 2014).

Developments in information technology (IT) have been and continue to be, a major driver of organizational transformation. IT has changed the structure and face of organizations in most industries and it is recognized that introducing and changing technology in an organization is not merely an IT issue (Jackson \& Harris, 2003). For example, the impact of ebusiness transformation of organizations is well documented. Technology has changed the way in which customers and suppliers interact with the outer face of the organization, and transformed the back office processes needed to support the external face of the front office activities. The wider implications of changing IT systems in organizations as an enabler of organizational change need to be considered.

The contribution of this chapter is the presentation of an organization architecture to explore the impact of IT-led change in morphing organizations. The framework of the organization architecture offers a coherent structure in which to consider organizational transformation in response to IT-led change, to structure analysis and evaluation of the aspects of an organization that may be affected by proposed changes to IT systems in an organization. The framework may also be used retrospectively to analyse how changes in IT have led to organizational transformation. The organizational architecture builds on the Mckinsey 7-S framework (Peters \& Waterman Jr., 2004) 
and considers the impact of IT changes to both formal elements of the organization such as organizational processes and informal elements such as social values. The application of the organization architecture is illustrated through case study examples from UK organizations.

The following section discusses organization identity. A business model is discussed showing the relationship between an organization and its trading environment focusing on the external face of the organization. The internal structures that support the external organization identity are then discussed. An organization architecture is presented as a model to explore the changes in the organization needed to accommodate IT and how an organization may be affected by changes to IT. The chapter concludes by considering the challenges of the third wave of IT-led change, predicted by Porter \& Heppelmann (2014), to organizational identity.

\section{BACKGROUND}

Identity is the most fundamental concept of humanity and is the essence of an organization, which emerges through communication and interaction between members of the organization (Koskinen, 2015). The act of identifying an organization establishes a conceptual boundary around a group of people, resources and activities. Defining an organization separates the organization linguistically from other things (Koskinen, 2015), creating an entity with a unique identity. The relationships between the organization, its customers, suppliers, competitors and trading partners can then be explored.

Whetten (2006) uses the phrase 'organizational identity claims' or 'referents' in relation to the attributes of an organization that form its identity. These are enduring attributes that reflect the core values of an organization and are tested by considering the question of whether the organization would be the same organization without a specific attribute.

In the same way that the view an individual holds about themselves may differ from the way that others see them, there is the identity of how others see the organization and how those inside the organization perceive the organization. Balmer (2008) uses the term corporate identity to reflect an external view of how the organization is perceived by those outside the organization, such as customers and the term organizational identity to reflect the internal view of how the organization is perceived by those within it. Koskinen (2015) uses similar terms to represent these two views and adds a third form of identity:

- company identity is how the organization presents itself to its environment.

- reflective identity is how the organization sees itself internally.

- substantive identity is the mechanism that keep the different parts of the organization focused as a single unit.

An organization's identity is created by the decisions and practices in an organization, which in turn influence the identity. Koskinen (2015) describes identity as the hidden face of strategy. Accurate identification of organizations is essential (Whetten, 2006) and attention to the organizational identity is particularly needed during periods of change (Albert \& Whetten, 1985). The following sections discuss two models: the business model and organization architecture that reflect the company identity and internal substantive identity respectively.

\section{Business Model}

Organizations operate within an external trading context that is represented in a business model. All organizations have a business model (Andersén et al., 2015). A business model is a way of doing business focusing on the organization's competencies (DaSilva \& Trkman, 2014), reflecting the relationship between control and value in the organization (Ballon, 2007). Business models identify key aspects of an organization that determine how the organization positions itself in its market(s) and industry(ies) in order to create, maintain and reflect its unique identity.

Osterwalder et al., (2005) identified nine elements in a business model:

1. Value proposition (products and services offered by the organization).

2. Target customer segments.

3. Distribution channels (used to reach customers).

4. Relationship (links between organization and customer segments). 
5. Value configuration (arrangements of activities and resources)

6. Core competency (of organization exploited in business model).

7. Partner network (co-operative agreements with external parties).

8. Cost structure.

9. Revenue model (how it makes money).

Most of the elements identified by Osterwalder et al., (2005) focus on the external relationships of the organization. Koskinen (2015) suggests that although business models represent the external relationships of an organization, business models are not sufficient to understand the history and evolution of the organization, which contribute to the organization's identity. Although a business model may include some referents of company identity, it is insufficient for examining the organization's substantive identity and how the internal context will be affected organizational transformation.

Figure 1 shows a generic business model (Cox, 2014) comprising three sets, the organization, market and business environment situated within the wider business climate.

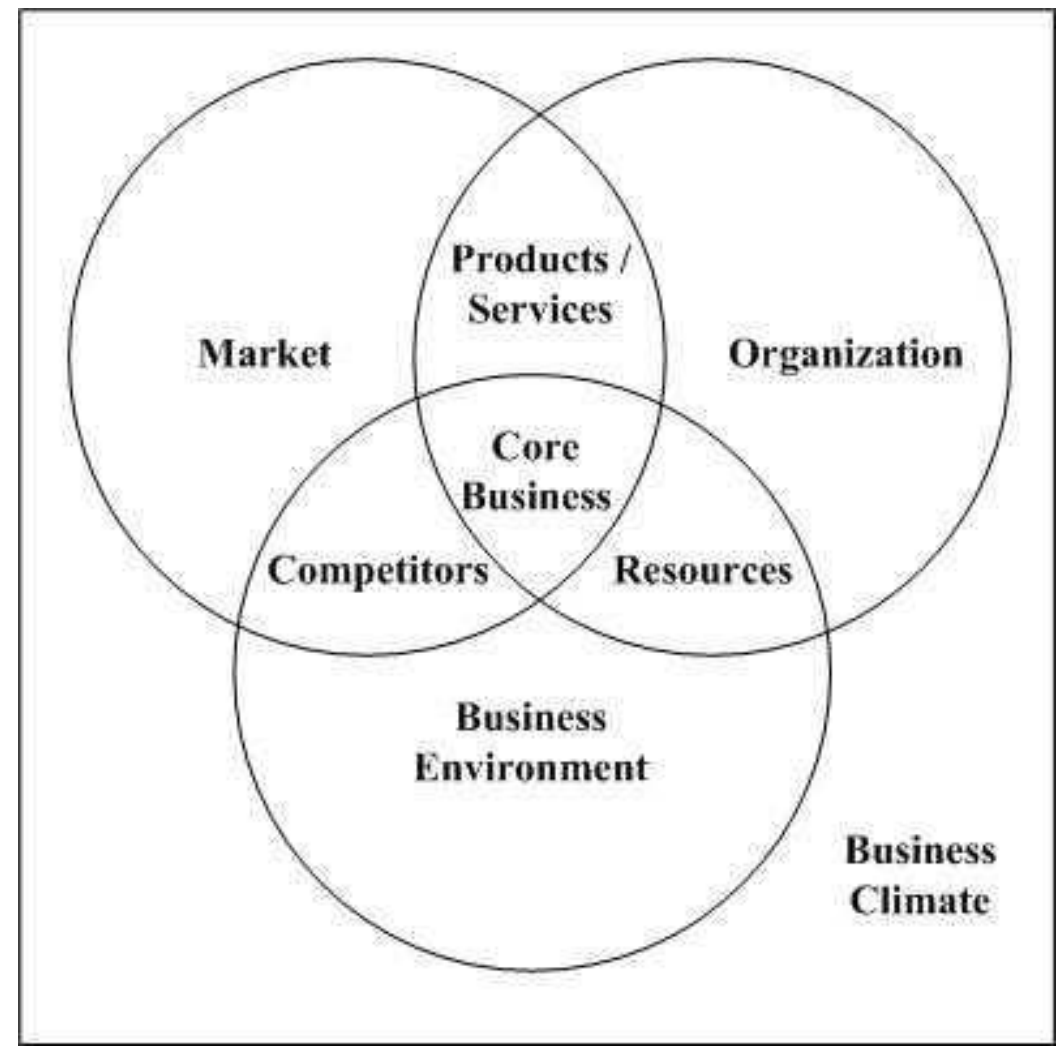

Figure 1: Generic business model (Cox, 2014)

The business model provides the context for the organization's identity and identifies the external stakeholders, which may provide opportunities and constraints for the organization achieving its vision. The organization architecture forms the context for substantive identity within the organization set of the business model and provides the contextual framework for activity in the organization; changes to the organization architecture trigger and facilitate organizational transformation. Organizational change may be initiated in response to external changes in the market, business environment or business climate, for example, changing customer expectations, changing industry standards or legislative requirements. Organizational change may also be internally initiated, for example, by new management.

The performance of an organization and the outcome of organizational change emerge from the interaction between the organization's structures, individuals within the organization and the organizational strategies, which form the context for technology use (Yeo \& Marquardt, 2015) in the organization architecture. Much of the research about organizational design focuses on organizational structures (Sherif et al., 2013). For example, Ethiraj \& Levinthal (2004) consider organizational design based on two choices: the number of departments and the assignment of 
functions to departments. Organizations need to have sufficient flexibility to enable them to respond to the demands and opportunities of innovations in IT, balanced with stability to maintain their unique identity. Sherif et al., (2013) describe an ambidextrous structure as one that allows organizations to move between organic and mechanic organizational structures depending on market conditions.

\section{Organization Architecture}

Business models focus externally on the relationship between the organization and its trading environment, in contrast the organization architecture focuses internally on the structures and components that maintain the external organization identity.

The organizational architecture is different to the organizational structure. Sherif et al., (2013) describe an organization architecture as a high level map of the organization that includes people, processes and technology. The formal and informal organization structure form part of the organization architecture. The organization structure groups resources, provides a boundary for activities to be controlled, and determines the flow of information, authority and decision-making responsibility through the organization. An organizational architecture creates behavioural space, which provides opportunities and constraints for organizational activities. The architecture provides a boundary for activity, shaping the organization. Saucer \& Willcocks (2004) emphasize that defining the organizational architecture is not a one-off task (like designing a building); it is a continuous process of adjustment to meet the changing needs of the business environment.

Sherif et al., (2013) suggest that the organization architecture includes three architectures:

- Business architecture: organizational capabilities (services, processes and information) translating the strategic objectives into processes and competences.

- Infrastructure architecture: technical capabilities (hardware and telecommunications) supporting business processes

- Application architecture: governance capabilities monitoring and controlling activities.

Waterman Jr. et al., (1980) proposed that organizational effectiveness emerges from the dynamic interactions between the organization's structure, strategy, systems, style (of management and culture), skills, staff resource (including morale, attitude, behaviour, training and appraisal) and subordinate goals (later renamed shared values (Peters \& Waterman Jr., 2004) representing the values underlying the mission of the organization). This became known as the Mckinsey 7-S framework@. Each area of the 7-S framework is connected to the others (Kaplan, 2005), demonstrating that change in any of the seven areas will trigger change in the other areas.

\section{Organization Change}

Changes in an organization can range from minor changes to improve efficiency through to the complete destruction and redesign of structures and systems (Senior \& Swailes, 2010). Ethiraj \& Levinthal (2004) differentiate between first-order change (incremental change within the existing organizational structure) and second-order change to the underlying structures to align with environmental demands. Dunphy \& Stace (1993) identify four types of change within this broad spectrum of minor modification to major redesign. Each type of change differs in terms of the scope and scale of the change in the organization. First, fine tuning involves minor adjustments, which may be restricted to one department and may be internally triggered, to improve organizational alignment of strategy, structure, people and processes. Second, increment adjustment may affect one or more departments with the aim of improving the operation of the organization by modifying strategies, structures and management processes in response to changes in the external environment. Third, modular transformation relates to the restructuring of one or more departments and changing the co-ordination of activities between departments. Fourth, corporate transformation involves revolutionary change of the strategy, structures and systems in the organization, requiring wide scale redesign of the organization, challenging organization identity. Organizational change is often triggered by IT.

\section{IT-LED CHANGE}

Organizations must adopt and embed information technology into their social practices in order to meet the changing demands and expectations of their trading environment. IT can lead to 
structural changes in organizations (Goksen et al., 2015) as technology can be used to change the flow of information, control and decision-making. Organizational participants respond to IT in different ways, leading to change in the organization architecture to accommodate the technology and posing threats to the organization's identity.

IT can constrain or enable change in organizations (Yeo \& Marquardt, 2015). IT has been deliberately used as a vehicle to initiate cultural change in organizations, for example, egovernment has been introduced with the aim of transforming public sector services (Yeo \& Ajam, 2010). However, the introduction of IT or changes to IT, can lead to both intentional and unintentional consequences in the organization (Yeo \& Marquardt, 2015).

The design of technological systems embodies business rules that constrain actions in an organization, though constraints can be resisted and lead to unintentional consequences. For example, Boudreau \& Robey (2005) discuss a case where a feature of the system was that it would automatically log-off users who did not interact with the system for a defined period in order to increase security. Users did not like the lack of freedom to leave the system unattended, partly because of the length of time taken to log-in. Users therefore devised ways to "beat the system" such as by asking others to simulate actions for them (Boudreau \& Robey, 2005). Although the intention was for the system feature to increase security, an unintended consequence of the system was that it decreased security as staff developed ways of working around the system controls.

Figure 2 presents a $2 \times 2$ grid to reflect the positive and negative impacts of IT on organizations. The grid forms four sectors:

Sector A: As in the log-in example (Bordreau \& Robey, 2005), technology can restrict actions, which may result in unintended consequences as staff seek ways to work around the restrictions.

Sector B: In contrast, positive side effects can emerge from technology through facilitating social improvisation and invention (Boudreau \& Robey, 2005).

Sector C: Positive planned improvements to organizational performance can emerge. For example, the electronic submission and retrieval of documents has been used to improve service delivery (Yeo \& Marquardt, 2015).

Sector D: Intentional imposed restrictions and monitoring controls can be implemented to impose standards and formalize practices. For example, in one case the requirement to store information in shared folders improved information access and also led to opportunities for collaboration through a virtual community (Yeo \& Marquardt, 2015). 


\begin{tabular}{|c|c|c|}
\hline 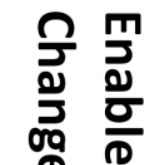 & B: Invention & C: Improvements \\
\hline \multirow[t]{2}{*}{ 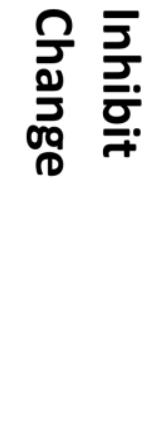 } & A: Workaround & D: Restrictions \\
\hline & $\begin{array}{l}\text { Unintentional } \\
\text { Consequences }\end{array}$ & $\begin{array}{c}\text { Intentional } \\
\text { Consequences }\end{array}$ \\
\hline
\end{tabular}

\section{Figure 2: Impact of IT on organizations}

The unintentional consequences arising from technology may result from both intended and unintended uses of technology by actors in the organization. For example, the inventive use of data entry fields overcame perceived limitations of the system but the misuse of data entry fields also leads to data quality issues (Bordreau \& Robey, 2005).

Yeo \& Marquardt (2015) suggest that enactment with technology leads to both innovation and disruption in work practices, which will impact organizational structure, strategy and performance. Technology can also lead to inequality and exclusion of some workers in the organization. The potential impact of technology adoption on organizations needs to be assessed to inform decisions about whether to implement the technology. Orlikowski (2007) criticizes studies of technology adoption that either adopt a techno-centric perspective of how technology impacts social practices, ignoring how technology is given meaning within a specific context, or adopt a human-centric perspective of how agents make sense of technology but implement a restricted view of technology. Orlikowski (2007) uses the term sociomateriality to refer to the emergent relationship between technology and human actors in the organization reflecting how technology loses its objective meaning as it becomes embedded in the social actions and practices of the actors in the organization. As actors make sense of the technology there is an interrelationship between the task and technology; the technology changes the task and the task changes the requirements and use of the technology (Carroll \& Rossen, 1992). Actors in the organization engage in collective sensemaking of technology (Yeo \& Marquardt, 2015) and it is through this enactment of technology that organizations change (Boudreau \& Robey, 2005). A framework is needed to explore how technology drives change in organizations.

\section{SOLUTIONS AND RECOMMENDATIONS}

Developments in IT provide new ways for organizations to interact with customers and other external parties, changing the external face of the organization. Organizations need a means to: 
- Examine how the internal structures of the organization need to be adjusted to support the changes to the organization's external face.

- Assess the potential consequences arising from the internal changes proposed.

- Reflect on the impact the changes may have on the organization's identity.

The organization architecture provides an abstraction of organizational factors that influence an organization's IT development capability (Sherif et al., 2013). IT can in turn also influence these factors in the organization architecture to lead change in the organization.

Organizations change over time, going through a series of phases of change. Cox et al., (2006) examined two cases of organizational transformation. The first case examined the organizational impact on a UK manufacturer following the implementation of e-business systems enabling collaboration between the manufacturer and the major supermarket chains. The second case explored the manufacturer's engagement in e-business with smaller retailers and the impact on the retailers. From these cases, eight dimensions of organizational transformation were identified, shown in the first column of Table 1.

These dimensions were also identified in analysis of the phases of change of a typical retail organization in the UK (Cox, 2014) as it moved from:

- Counter service (where customers asked staff for goods over a counter) to self service (where customers took goods from shelves and paid at a checkout before leaving the store).

- Self service to Internet service as customers purchased goods online.

- Internet service to Internet collaboration, as customers engaged in online communication with the store.

As the organization moved through these phases of change, the dimensions of change of the organization are shown in Table 1. This third case study is significant as it revealed that non-IT related change (the move from counter service to self service in the store) affected the same dimensions of the organization as the technology-related change (such as the introduction of online retailing).

\begin{tabular}{|l|l|l|l|}
\hline Dimension & $\begin{array}{l}\text { Counter Service to } \\
\text { Self Service }\end{array}$ & $\begin{array}{c}\text { Self Service to Internet } \\
\text { Service }\end{array}$ & $\begin{array}{c}\text { Internet Service to } \\
\text { Internet Collaboration }\end{array}$ \\
\hline People & Roles redefined. & $\begin{array}{l}\text { Procedural roles, lacking } \\
\text { flexibility. }\end{array}$ & $\begin{array}{l}\text { Collaborative roles working } \\
\text { with others online. }\end{array}$ \\
\hline Skills & $\begin{array}{l}\text { Broader and less } \\
\text { specialized knowledge } \\
\text { needed. }\end{array}$ & $\begin{array}{l}\text { Less personal, online } \\
\text { communication skills } \\
\text { needed. }\end{array}$ & $\begin{array}{l}\text { Develop relationships } \\
\text { through ability to } \\
\text { communicate online. }\end{array}$ \\
\hline Practices & $\begin{array}{l}\text { Way of shopping } \\
\text { changed for customers } \\
\text { and staff. }\end{array}$ & $\begin{array}{l}\text { Way of shopping changed } \\
\text { for customers and staff. }\end{array}$ & $\begin{array}{l}\text { Information shared through } \\
\text { working in partnership. }\end{array}$ \\
\hline Processes & $\begin{array}{l}\text { Front office processes } \\
\text { changed: sales, } \\
\text { purchasing and } \\
\text { payment changed. }\end{array}$ & $\begin{array}{l}\text { Back office processes } \\
\text { changed: stock control, } \\
\text { packing and distribution. }\end{array}$ & $\begin{array}{l}\text { Front office processes to } \\
\text { facilitate collaboration and } \\
\text { back office processes to } \\
\text { act on data captured } \\
\text { changed. }\end{array}$ \\
\hline Trust & $\begin{array}{l}\text { Customers trusted to } \\
\text { pay for items before } \\
\text { leaving store. }\end{array}$ & $\begin{array}{l}\text { Organization trusted to } \\
\text { provide accurate } \\
\text { shopping data, honour } \\
\text { transaction and keep } \\
\text { personal data secure. }\end{array}$ & $\begin{array}{l}\text { Customers and } \\
\text { organizations trust that } \\
\text { data are accurate and not } \\
\text { misused. }\end{array}$ \\
\hline Data & $\begin{array}{l}\text { Better product labelling } \\
\text { needed on shelves. }\end{array}$ & $\begin{array}{l}\text { Accurate data needed } \\
\text { about the product, } \\
\text { shopping process and }\end{array}$ & $\begin{array}{l}\text { Challenges of technical } \\
\text { capability and semantic } \\
\text { issues arose. }\end{array}$ \\
\hline
\end{tabular}




\begin{tabular}{|l|l|l|l|}
\hline Security & $\begin{array}{l}\text { Risks to product } \\
\text { security increased as } \\
\text { customers had direct } \\
\text { access to stock. }\end{array}$ & $\begin{array}{l}\text { Risks to information } \\
\text { security increased and } \\
\text { security focuses on } \\
\text { restricting access to } \\
\text { information and } \\
\text { transactions rather than } \\
\text { physical products. }\end{array}$ & $\begin{array}{l}\text { Security focuses on } \\
\text { enabling legitimate access } \\
\text { to information and } \\
\text { communications. }\end{array}$ \\
\hline Infrastructure & $\begin{array}{l}\text { Shelving and counters } \\
\text { in store changed style } \\
\text { and placement. }\end{array}$ & $\begin{array}{l}\text { Technical infrastructure } \\
\text { development. }\end{array}$ & $\begin{array}{l}\text { Compatibility and } \\
\text { integration of data systems } \\
\text { required. }\end{array}$ \\
\hline
\end{tabular}

Table 1: Morphing dimensions of a retail organization

Analysis of these dimensions showed that some of the dimensions related to formal components of the organization such as its infrastructure and security, and some elements referred to informal components such as trust.

The findings from these case studies were compared with the components of the 7-s framework (Peters \& Waterman Jr., 2004) in Table 2. Although some overlap in areas such as staff and skills was identified, the analysis of the case studies highlighted more practice-based issues from the perspective of the staff affected by the organizational change. A key component that is not included in the 7-S framework is consideration to the changes to data and information in the organization and the role of data and information in the change process, which are particularly important in IT-led change. Table 1 shows how issues of data, security and trust were identified as key components affected by IT-related changes in the organization.

A further case study was conducted exploring the impact of e-business in a UK organization (Cox, 2013). This led to further refinement of the organizational components affected by e-business. This list was then used to plan the introduction of social media systems in an organization taking into account the impact on the organization. In these five cases, the organizational structure was not directly affected by the e-business and social media systems introduced into the organizations. This led to the development of the dimensions to form the components in the organization architecture in Figure 3, which includes the elements of business architecture and infrastructure architecture of Sherif et al., (2013). Referents of identity are different in each organization but the organization architecture provides a general framework in which to assess organizational transformation and the potential impact on organization identity. Components of the organization architecture are embedded in the culture and values of the organization, shown in Figure 3. Change to the organization architecture can be triggered by change to any of the architecture's components. Before a component in the architecture is changed, the morphing organization will need to consider to what extent the change aligns with the organization's culture or challenges its identity.

\begin{tabular}{|c|c|c|c|c|}
\hline $\begin{array}{c}\text { Case } \\
\text { Studies 1 } \\
\text { and 2 (Cox } \\
\text { et al,. } \\
\text { (2001), Case } \\
\text { Study 3 } \\
\text { (Cox, 2014) }\end{array}$ & $\begin{array}{c}\text { Framework } \\
\text { (Peters \& } \\
\text { Waterman } \\
\text { Jr., 2004) }\end{array}$ & $\begin{array}{c}\text { Case } \\
\text { Studies 4 } \\
\text { and 5 (Cox, } \\
\text { 2013) }\end{array}$ & $\begin{array}{c}\text { Formal } \\
\text { Components } \\
\text { of } \\
\text { Organization } \\
\text { Architecture }\end{array}$ & $\begin{array}{c}\text { Informal } \\
\text { Components } \\
\text { of } \\
\text { Organization } \\
\text { Architecture }\end{array}$ \\
\hline People & Staff & People & People & \\
\hline Skills & Skills & Skills & & Skills \\
\hline Practices & & Practices & & Practices \\
\hline Processes & & Processes & Processes & \\
\hline
\end{tabular}




\begin{tabular}{|c|c|c|c|c|}
\hline Trust & & Trust & & Trust \\
\hline Data & & Data & Data & \\
\hline Security & & Security & Security & \\
\hline \multirow[t]{13}{*}{ Infrastructure } & & Infrastructure & Infrastructure & \\
\hline & Structure & & & \\
\hline & Strategy & Strategy & Strategy & \\
\hline & Systems & Systems & Systems & \\
\hline & Style & $\begin{array}{l}\text { Shared } \\
\text { Values }\end{array}$ & & Values \\
\hline & $\begin{array}{c}\text { Subordinate } \\
\text { Goals }\end{array}$ & & & \\
\hline & & & Technology & \\
\hline & & & Culture & \\
\hline & & & & Vision \\
\hline & & & & $\begin{array}{l}\text { Human } \\
\text { Activity } \\
\text { Systems }\end{array}$ \\
\hline & & & & $\begin{array}{c}\text { Socio- } \\
\text { technical }\end{array}$ \\
\hline & & & & Architecture \\
\hline & & & & Information \\
\hline
\end{tabular}

Table 2: Comparison of organizational components 


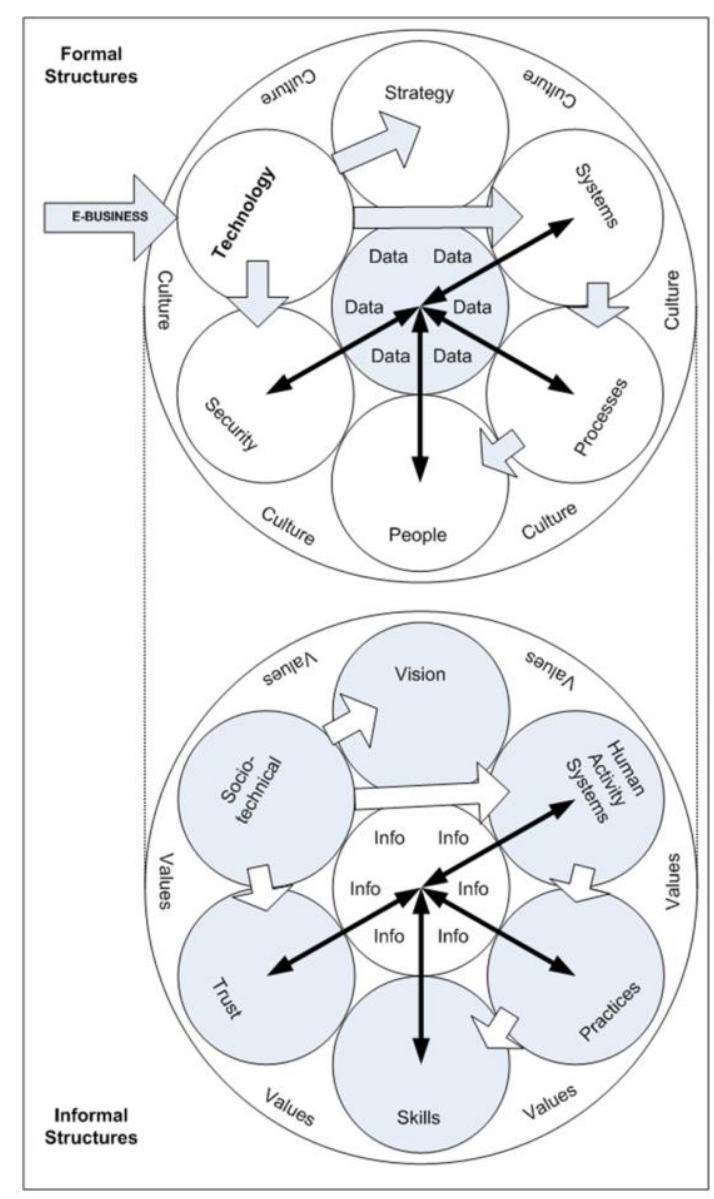

Figure 3: Organization architecture (Cox, 2014)

The organization architecture provides a framework to explore how changes to one component such as technology lead to changes of other components in the organization and whether changes to a specific component are consistent with the organization's identity. For example, the introduction of social media technology changed the organization strategy and vision in terms of how the organization related to its external stakeholders in case study 5 . The introduction of social media changed communication processes and practices, increasing threats to data security requiring additional software controls to be introduced. The organization had to trust that staff would not disclose confidential information through social media. As social media was integrated into existing systems and processes as another communication mechanism, staff needed to develop new skills in using the media. One of the organization's core values was consistency; consistency in information and service. The introduction of social media challenged this value as in responding to social media messages quickly, staff mistakenly published inconsistent information to customers. Technology is situated within the culture of organizations and has to be used in ways consistent with the organization's values in order to ensure that the organization's identity is maintained.

\section{FUTURE RESEARCH DIRECTIONS}

Organizational identity is an important concept, distinct from branding, to establish relationships between the organization and external stakeholders. As trade and communication is increasingly mediated by Internet technologies, further work is needed to establish how organizational identity is reflected, perceived and maintained through online activities. Organizations have been transformed and organizational identifies have been challenged by developments in IT and by the speed with which IT has become embedded into society. As technology continues to become increasingly ubiquitous and the organizational boundary becomes blurred, the context in which technology is used by actors in the organization needs to be considered. 
Porter \& Heppelmann (2014) describe three waves of IT-driven transformation. The first wave focused on automating activities in the value chain, leading to the standardization of processes. The second wave focused on co-ordinating and integrating activities in the value chain. A third wave of information IT-led change is now reshaping organizational and industry boundaries. The third wave integrates IT into products sold, capturing usage data about the product's functions and performance, enabling designs to be changed after products have been manufactured and sold. Porter \& Heppelmann (2014) refer to the technology stack as the technology infrastructure needed to support smart connected products, comprising five levels: hardware, software applications, operating system, network communication and product cloud. Further understanding of organizational architectures is needed in order to explore how organizations can collaborate in the different levels of the technology stack to deliver smart connected products. As organizations collaborate within the technology stack, the impact on organizational identity needs to be considered.

\section{CONCLUSION}

IT has been used to lead organizational transformation, however, as actors in the organization seek to make sense of how the technology affects daily practices, technology becomes used in ways which were unintended. Boudreau \& Robey (2005) therefore argue that as technology can result in unintended consequences, technology has a limited role in transforming organizations.

Technology forms one component of the organizational architecture. Change to any component in the organizational architecture has the potential to trigger change in other components. A framework has been presented, based on analysis of IT-led transformation in five case studies, to assist organizations in planning how a change in technology may affect other components of the organization architecture.

Porter \& Heppelman (2014) suggest that organizations need to focus on the question, what business are we in? The business model helps organizations to explore the external face presented to the trading environment. The organization architecture helps organizations to explore the internal components that sustain the organization's identity. Continued developments in technology will consistently challenge the shape, identity and practice of organizations. Further work is therefore needed to explore the longitudinal impact of changes to the organizational architecture and identity of morphing organizations within an ever changing technological context.

\section{REFERENCES}

Albert, S., \& Whetten, D. A. (1985). Organizational identity. Research in Organizational Behaviour, 7, 263-295.

Andersén, J., Ljungkvist, T., \& Svensson, L. (2015). Entrepreneurially oriented in what? A business model approach to entrepreneurship. Journal of Small Business and Enterprise Development, 22(3), 433-449.

Ballon, P. (2007). Business modelling revisited: The configuration of control and value. info, 9(5), 6-19.

Balmer, J. M. T. (2008). Identity based views of the corporation. European Journal of Marketing, 42(9/10), 879-906.

Boudreau, M-C., \& Robey, D. (2005). Enacting integrated information technology: A human agency perspective. Organization Science, 16(1), 3-18.

Carroll, J, M., \& Rossen, M. B. (1992). Getting around the task-artifact cycle: How to make claims and design by scenario. ACM Transactions on Information Systems, 10(2), 181-212.

Cox, S. A. (2013). E-business planning in morphing organizations: Maturity models of business transformation. In E. Y. Li., S. Loh, C. Evans, \& F. Lorenzi (Eds.), Organizations and social networking: utilizing social media to engage consumers (pp. 286-312). IGI Global.

Cox, S. A. (2014). Managing information in organizations: A practical guide to implementing an information management strategy. Basingstoke, UK: Palgrave Macmillan. 
Cox, S. A., Krasniewicz, J. A., Perkins, J. S., \& Cox, J. A. (2006). Modelling the organisational transformation associated with implementing e-business collaborative systems in the supply chain. In Proceedings of the British Academy of Management Conference (BAM2006) in Association with the University of Ulster and Queen's University. Belfast.

DaSilva, C., \& Trkman, P. (2014). Business model: What it is and what it is not. Long Range Planning, 47(6), 379-389.

Dunphy, D., \& Stace, D. (1993). The strategic management of corporate change. Human Relations, 46(8), 905-918.

Ethiraj, S. K., \& Levinthal, D. (2004). Bounded rationality and the search for organizational architecture: An evolutionary perspective on the design of organizations and their evolvability. Administrative Science Quarterly, 49, 404-437.

Goksen, Y., Cevik, E., \& Avunduk, H. (2015). A case analysis on the focus of the maturity models and information technologies. In The Economies of Balkan and Eastern Europe Countries in the Changed World, Procedia Economics and Finance, (vol. 19, pp. 208-216). Nis, Serbia.

Jackson, P., \& Harris, L. (2003). E-business and organisational change: Reconciling traditional values with business transformation. Journal of Organizational Change, 16(5), 497-511.

Kaplan, R. S. (2005). How the balanced scorecard complements the McKinsey 7-s model. Strategy \& Leadership, 33(3), 41-46.

Koskinen, K. U. (2015). Identity change in organizations: A philosophical exposition. International Journal of Organizational Analysis, 23(4), 621-636.

Orlikowski, W. J. (2007). Sociomaterial practices: Exploring technology at work. Organization Studies, 28(9), 1435-1448.

Osterwalder, A., Pigneur, Y., \& Tucci, C. L. (2005). Clarifying business models: Origins, present, and future of the concept. Communications of the Association for Information Systems, 16, article 1, Retrieved October 14, 2015, from http://aisel.aisnet.org/cais/vol16/iss1/1

Peters, T. J., \& Waterman Jr., R. H. (2004). In search of excellence: Lessons from America's best run companies, Second edition, New York: Harper Collins.

Porter, M. E., \& Heppelmann, J. E. (2014). How smart, connected products are transforming competition. Harvard Business Review, 92(11), 64-88.

Saucer, C., \& Willcocks, L. (2004). Strategic alignment revisited: Connecting organizational architecture and IT infrastructure. In Proceedings of the $37^{\text {th }}$ Hawaii International Conference on System Sciences (pp. 1-10). Hawaii.

Senior, B., \& Swailes, S. (2010). Organisational change. Fourth edition, Harlow: Pearson.

Sherif, K., Tsado, L., Zheng, W., \& Airhia, B. (2013). An exploratory study of organization architecture and the balance between exploration and exploitation of knowledge. Vine: The Journal of Information and Knowledge Management Systems, 43(4), 442-461.

Waterman Jr., R. H., Peters, T. J., \& Phillips, J. R. (1980). Structure is not organization. Business Horizons, 23(3), 14-26.

Whetten, D. A. (2006). Albert and Whetten revisited: Strengthening the concept of organizational identity. Journal of Management Inquiry, 15(3), 219-234.

Yeo, R. K., \& Marquardt, M. (2015). Think before you act: Organizing structures of action in technology-induced change. Journal of Organizational Change Management, 28(4), 511-528.

Yeo, R. K., \& Ajam, M. Y. (2010). Technological development and challenges in strategizing organizational change. International Journal of Organizational Analysis, 18(3), 295-320. 


\section{KEY TERMS AND DEFINITIONS}

Business Model: An external representation of how the organization makes money and creates value through interactions with customers, suppliers and partners in the external trading environment.

Constitutive Entanglement: Complex configurations of inter-related concepts.

Context: The setting within which organizations, people, processes, information and events are interpreted. Context is an emergent property derived from interrelated dynamic states at a point in time.

Morphing Organization: An organization that changes the outer face the organization displays to the world by changing internal structures and processes within the organization to facilitate and support the external face, whilst seeking to maintain organizational identity.

Organization Architecture: An internal representation of the formal and informal components of the organization that provide the behavioural space for the organization's activities.

Organization Identity: A set of enduring attributes, which emerge through interaction with the organization, representing the spirit of the organization.

Organization Structure: The way in which resources are grouped in the organization to determine the control of activities, flow of information, and authority and responsibility for decision-making.

Organization Transformation: Significant changes to more than one component of the organization architecture that directly impact more than one department or function in the organization.

Sociomateriality: The view that technology and human interaction with technology are interlinked such that the two concepts cannot be objectively studied separately due to constitutive entanglement.

Workaround: A way of working to overcome perceived omissions, limitations or problems with formally defined working practices that are often embedded in IT systems.

\section{ADDITIONAL READINGS}

Cox, S. A. (2014). Managing information in organizations: A practical guide to implementing an information management strategy, Basingstoke, UK: Palgrave Macmillan.

DaSilva, C. M., \& Trkman, P. (2014). Business model: What it is and what it is not, Long Range Planning, 47(6), 379-389

lansiti, M., \& Lakhani, K. R. (2014). Digital ubiquity: how connections, sensors, and data are revolutionizing business, Harvard Business Review, 92(11), 91-99.

Leonardi, P. M., Nardi, B. A., \& Kallinikos, J. (Eds.). (2012). Materiality and organizing: Social interaction in a technological world, Oxford, UK: Oxford University Press.

Osterwalder, A. (2010). Business model generation: A handbook for visionaries, game changers, and challengers, New Jersey: John Wiley \& Sons.

Rothwell, W. J., Stavros, J. M., \& Sullicva, R. L. (Eds.). (2016). Practicing organization development: Leading transformation and change, New Jersey: John Wiley \& Sons.

Schultz, M., Maguire, S., Langley, A., \& Tsoukas, H. (Eds.). (2012). Constructing identity in and around organizations, Oxford, UK: Oxford University Press.

Stanford, N. (2013). Organization design: Engaging with change, Oxon, UK: Routledge. 